TITLE:

\title{
Hospital volume and outcomes of cardiothoracic surgery in Japan: 2005-2009 national survey.
}

\section{$\operatorname{AUTHOR}(\mathrm{S}):$}

Sakata, Ryuzo; Kuwano, Hiroyuki; Yokomise, Hiroyasu

\section{CITATION:}

Sakata, Ryuzo ... [et al]. Hospital volume and outcomes of cardiothoracic surgery in Japan: 2005-2009 national survey.. General thoracic and cardiovascular surgery 2012, 60(10): 625638

ISSUE DATE:

2012-10

URL:

http://hdl.handle.net/2433/164079

\section{RIGHT:}

The final publication is available at www.springerlink.com; この論文は 出版社版でありません。引用の際には出版社版をご確認ご利用くださ $\omega_{\circ}$; This is not the published version. Please cite only the published version. 


\title{
Hospital Volume and Outcomes of Cardiothoracic Surgery in Japan: 2005 to 2009 National Survey
}

\author{
Authors \\ Ryuzo Sakata, MD, $\mathrm{PhD}^{1}$ \\ Hiroyuki Kuwano, $\mathrm{MD}, \mathrm{PhD}^{2}$ \\ Hiroyasu Yokomise, $\mathrm{MD}, \mathrm{PhD}^{3}$
}

\begin{abstract}
Affiliations
1) Department of Cardiovascular Surgery, Kyoto University Graduate School of Medicine, Kyoto, JAPAN

2) Department of Surgical Science (Surgery I), Gunma University Graduate School of Medicine, Maebashi, JAPAN

3) Department of General Thoracic, Breast and Endocrinological Surgery, Faculty of Medicine, Kagawa University, Kagawa, JAPAN

\author{
Address for correspondence \\ Ryuzo Sakata, MD, PhD \\ Department of Cardiovascular Surgery, \\ Kyoto University Graduate School of Medicine \\ 54 Shogoin-Kawahara, Sakyo, Kyoto, 606-8507 JAPAN \\ Tel: +81-75-751-3780 Fax: +81-75-751-4097 \\ E-mail: sakatar@kuhp.kyoto-u.ac.jp
}




\begin{abstract}
Objectives: To elucidate the relationship between hospital volume and cardiothoracic surgical outcomes in Japan using the annual survey data, obtained between 2005 and 2009, collected by the Committee for Scientific Affairs of the Japanese Association for Thoracic Surgery.

Methods: The relationship between hospital volume and 30-day mortality was analyzed using a logistic regression model. The empirical Bayes (EB) method was also used to stabilize any large variation resulting from a small sample size. If hospitals whose lower limit of the EB mortality 95\% confidence interval was above the mean EB mortality of all hospitals, they were defined as hospitals with "inferior outcomes". The surgical procedures analyzed were coronary artery bypass grafting (CABG: elective + emergency), elective CABG, emergency CABG, single-valve surgery, surgery for acute type A dissection, open heart surgery for newborns, open heart surgery for infants, surgery for lung cancer, and surgery for esophageal cancer.

Results: There were large variations in 30-day mortality for all procedures, particularly in the lower-volume hospitals. There was a significant but weak inverse correlation between the hospital volume and the 30-day mortality rate for elective CABG, emergency CABG, single valve surgery, surgery for acute type A dissection, and lung cancer surgery. There was no correlation between hospital volume and the 30-day morality for open heart surgery for newborns and infants, and esophageal cancer surgery. After EB method adjustment, there was no hospital with inferior outcomes for conventional operations such as elective CABG, single-valve surgery and lung cancer surgery. The ratio of hospitals with inferior outcomes in more complex procedures was $1.8 \%$ for open heart surgery for newborns, $0.8 \%$ for open heart surgery for infants, and $0.2 \%$ for esophageal cancer surgery.
\end{abstract}

Conclusion: There is a weak or no inverse correlation between the hospital volume and the 
mortality in cardiothoracic surgery in Japan. Most of the low-volume hospitals are not associated with inferior outcomes. The performance of the lower-volume hospitals should be carefully scrutinized with using risk adjustment. 


\section{INTRODUCTION}

Several reports have focused on the relationship between hospital volume and surgical outcomes 1234 . Most of the reports have shown that a higher hospital volume is associated with better outcomes. Accordingly, the Japanese Ministry of Health, Labor, and Welfare decided to reduce by $30 \%$ the health insurance reimbursement for hospitals that had a cardiac surgery volume of less than 100 surgeries per year in 2002; this reduction occurred because US or European evidence showed that a lower hospital volume is associated with inferior surgical outcomes . However, several Japanese reports indicated that a lower hospital volume was not necessarily associated with inferior outcomes ${ }^{5}{ }^{6}$. There were large outcome variations in low-volume hospitals, and several lower-volume hospitals showed satisfactory outcomes. Thereafter, the regulation was abolished in 2006.

In 2007, the Committee for Scientific Affairs of the Japanese Association for Thoracic Surgery (JATS) reported the relationship between the hospital volume and the 30-day cardiothoracic surgery mortality in Japan, based on nationwide data collected between 2000 and $2004^{6}$. The report indicated that there were inverse correlations between the hospital volume and the outcomes, but this report simultaneously raised an issue that there was a wide variety of mortality particularly in the lower-volume hospitals. In small-volume hospitals, one death could drastically affect the mortality rate, and the data for crude mortality rates could also be drastically affected by this scattered data ${ }^{7}$. In addition, recent improvements in surgical techniques, anesthesia, and perioperative care may influence the hospital volume-outcome relationship in Japan. Thus, in the present report, we sought to elucidate the latest hospital volume-outcome relationship in Japan, and to more accurately adjust the outcome variations, particularly in lower-volume hospitals, by using the empirical Bayes (EB) estimation ${ }^{8}$. 


\section{PATIENTS AND METHODS}

The JATS Committee for Scientific Affairs conducts an annual cardiothoracic and esophageal surgery survey at its Japanese member institutions. The data were collected annually from each institution from 2005 to $2009^{9} 10111213$, as previously described ${ }^{6}$. Using the data, we evaluated the relationship between the hospital volume and the mortality observed in 10 types of surgeries, as previously reported ${ }^{6}$. The average response rates from the participating institutions during the study period were $96.7 \%$ for cardiac surgery, $94.0 \%$ for lung surgery, and $91.1 \%$ for esophageal surgery.

\section{Statistical analysis}

Case volume was determined using the mean number of cases each year for 5 years. Institutions providing data for a minimum of 4 years were included in the analysis. Based on the relationship between the hospital volume and 30-day mortality, scatter diagrams were prepared. The scatter diagram vertical axis represents the 30-day mortality, and the horizontal axis represents the average annual hospital volume (average annual institutional case volume). One dot represents one institution. The unstratified volume-outcome relationship for all patients with a procedure, irrespective of their institutions, was assessed using the Pearson's correlation coefficient method. Risk adjustment was not done.

The logistic regression model was used to represent the volume categories using the dummy variables and to estimate the volume effect. To account for the 5-year longitudinal data, generalized estimating equations ${ }^{14}$ were used to estimate parameters and standard errors. The dummy variables were used in the model to represent the years, and the effects for each year were estimated. The odds ratio (OR) was calculated in relation to the volume of the highest-volume centers, which was considered to be 1.00 . The OR and mortality are cited in the 
Tables corresponding to each Figure. Statistical significance was conferred only when the lower limit of the $95 \%$ confidence interval $(95 \% \mathrm{CI})$ was $>1.00$, which is marked with an asterisk in the corresponding table.

We calculated the empirical Bayes (EB) and the 95\% confidence interval of the predicted EB estimates for the hospital mortality rates, as previously described ${ }^{78}$. The EB estimate is a technique used to stabilize the crude estimates close to the estimate for the whole sample. The EB-mortality is the mortality adjusted using the EB estimates. The Pearson's correlation coefficient between the hospital volume and the EB-mortality rate was calculated for the total acquired heart disease and elective CABG. In addition, we evaluated the hospitals with an inferior outcomes corresponding to a high mortality, which are defined as hospitals whose lower limit of the EB mortality $95 \%$ CI is above the average EB mortality of all the hospitals. This means the there is a greater than $95 \%$ probability of a negative outcome at the hospital. All $\mathrm{P}$ values were two-sided, and all analyses were performed with SAS version 9.2 (SAS Institute, Cary, NC, USA).

\section{RESULTS}

The total number of patients and corresponding hospitals, and the mean mortality rate of patients who underwent each operation between 2000 and $2004{ }^{6}$ and between 2005 and 2009 are listed in Table 1. A total of 141,181 patients underwent surgery for acquired heart disease (CABG, single valve, and acute type A dissection) at 522 hospitals between 2005 and 2009. A total of 13,074 patients underwent congenital heart surgery (newborns and infants). A total of 128,848 patients underwent lung cancer surgery at 647 hospitals, and there were a total of 24,224 patients who underwent esophageal cancer surgery in 493 hospitals .

When the 2000 to 2004 and the 2005 to 2009 outcomes are compared, the total number of 
surgeries for acquired heart disease decreased from 153,616 to 141,181 . The reduction was because both the number of elective and emergency CABG surgeries decreased between 2005 and 2009 compared to 2000 to 2004. However, the overall amount of operations increased except for that of CABG. The number of surgeries for newborns and infants increased, while the number of surgeries at the corresponding hospitals decreased. The mean 30-day mortality was reduced in all types of surgery; specifically, the mortality drastically decreased in open heart surgery for newborns (from $19.8 \%$ to $11.8 \%$ ) and in esophageal cancer surgery (from $5.80 \%$ to $1.98 \%)$.

\section{Surgery for acquired heart disease}

The scatter diagram and the corresponding Table in Figure 1 show the relationship between the hospital volume and the 30-day mortality rate in patients who underwent surgery for acquired heart disease. A total of 141,181 patients who underwent surgery at 522 institutions had an average mortality of $3.40 \%$. Among them, 65 hospitals had more than the average of 100 surgeries per year, with a corresponding patient mortality of $2.15 \%$; those with fewer than 25 cases had a higher patient mortality of $4.45 \%$ (OR [95\% CI]: 1.90 [1.52-2.39]). This means the lowest-volume hospitals were associated with 1.90 times higher odds of a negative outcome compared with the highest-volume hospitals. Similarly, patients in the 25 to 49 volume group and the 50 to 74 volume group had significantly higher mortality compared with the highest-volume group. Among the lower-volume hospitals, the patient mortality varied widely; however, most of the hospitals' patient mortality was under $10 \%$. Only a few hospitals had extremely high patient mortality. Pearson's correlation coefficient for the volume-outcome relationship was $-0.186(\mathrm{p}<0.001)$. 


\section{Total CABG (elective and emergency)}

A total of 85,600 patients underwent CABG surgery at 518 institutions, and had an average mortality of $2.15 \%$. Nineteen hospitals $(3.7 \%)$ had more than the average of 100 surgeries per year with a patient mortality of $1.00 \%$; those with fewer than 25 cases had a higher patient mortality of $2.72 \%(2.52$ [1.83-3.48]; Figure 2$)$. The mortality also varied widely among the lowest-volume hospitals, but several hospitals in the lowest-volume had 0\% patient morality. The patients at hospitals with 1 to 24 and 25 to 49 surgeries per year had a higher mortality compared with patients at the highest-volume hospitals. Pearson's correlation coefficient for the volume-outcome relationship was $-0.168(\mathrm{p}<0.001)$.

\section{Elective CABG}

A total of 72,937 patients underwent elective CABG surgery at 518 institutions, and had an average mortality of $1.12 \%$. Twelve hospitals $(2.3 \%)$ had more than the average of 100 surgeries per year with a patient mortality of $0.45 \%$; those with less than 25 cases had higher mortality of $1.35 \%$ (2.51 [1.69-3.73]; Figure 3). The patient mortality varied widely among the lowest-volume hospitals, but most of the mortality was under 5\%. The patients at hospitals with a volume of 1 to 24 and 25 to 49 surgeries per year had a higher mortality compared with the highest-volume hospitals. Pearson's correlation coefficient for the volume-outcome relation was $-0.133(\mathrm{P}<0.001)$.

\section{Emergency CABG}

A total of 12,663 patients underwent emergency CABG surgery at 482 institutions, and had an average mortality of $8.69 \%$. Seventeen hospitals $(3.5 \%)$ had more than the average of 20 surgeries per year, with a patient mortality of $4.51 \%$; those with less than 5 cases had a higher 
mortality of $10.50 \%$ (2.24 [1.57-3.19]; Figure 4). The mortality varied widely among the lowest-volume hospitals (from $0 \%$ to $100 \%$ ). The patients at hospitals with a volume of 1 to 4 and 5 to 9 surgeries per year had a higher mortality compared with the highest-volume hospitals. Pearson's correlation coefficient for the volume-outcome relationship of the whole group was $-0.169(\mathrm{p}<0.001)$.

\section{Single-valve surgery}

A total of 41,486 patients underwent single-valve surgery at 514 institutions, and had an average mortality of $3.21 \%$. Ten hospitals $(1.9 \%)$ had more than the average of 60 surgeries per year, with a patient mortality of $1.60 \%$; those hospitals with less than 15 cases had a higher patient mortality $(3.80 \%)$ compared to those with more surgeries $(2.01$ [1.45-2.78]; Figure 5). The patient mortality varied among the lowest-volume hospitals, but most of the hospitals had a patient mortality of less than $10 \%$. The patients at hospitals with a volume of 1 to 14 and 15 to 29 surgeries per year had a higher mortality compared with the highest-volume hospitals. Pearson's correlation coefficient for the volume-outcome relationship was $-0.150(\mathrm{p}<0.001)$.

\section{Surgery for acute type A dissection}

A total of 14,095 patients underwent surgery for acute type A dissection at 477 institutions, and had an average mortality of $13.41 \%$. Twenty hospitals $(4.2 \%)$ had more than the average of 20 surgeries per year, with a patient mortality of $9.7 \%$; hospitals with fewer than 5 surgeries had higher patient mortality (16.1\%) compared with those with a higher number of cases (1.48 [1.14-1.93]; Figure 6). The mortality varied widely among the low- and middle-volume hospitals (from $0 \%$ to $100 \%$ ). Patients at the lowest volume hospital had a higher mortality compared with the highest-volume hospitals. Pearson's correlation coefficient for the 
volume-outcome relationship was $-0.176(\mathrm{p}<0.001)$.

\section{Open heart surgery for newborns}

A total of 2825 newborn patients underwent open heart surgery at 105 institutions, and had an average mortality of $11.80 \%$. Five hospitals $(4.8 \%)$ had more than the average of 20 surgeries per year, with a patient mortality of $6.35 \%$; hospitals with fewer than 5 surgeries had a higher mortality of $13.5 \%$ (2.46 [1.45-4.17]; Figure 7). The mortality varied widely among the lowand middle-volume hospitals (from 0\% to 100\%). Patients at the lowest volume hospital had a higher mortality compared with the highest-volume hospitals. Pearson's correlation coefficient for the volume-outcome relationship was $-0.108(\mathrm{p}=0.273)$. There was no significant correlation between the hospital volume and the mortality in open heart surgery for newborns.

\section{Open heart surgery in infants}

A total of 10,249 infant patients underwent open heart surgery at 115 institutions, and had an average mortality of $3.78 \%$. Nine hospitals $(7.8 \%)$ had more than the average of 50 surgeries per year with a patient mortality of $1.36 \%$; those with less than 10 cases had patient mortality of 5.26\% (3.24 [1.53-6.85]; Figure 8). The patients at hospitals with a volume of 1 to 9 and 10 to 19 surgeries per year had a higher mortality compared with the highest-volume hospitals. Pearson's correlation coefficient for the volume-outcome relationship was $-0.151(p=0.149)$. There was no significant correlation between the hospital volume and the mortality in open heart surgery for infants.

\section{Lung cancer surgery}

A total of 128,848 patients underwent lung cancer surgery at 647 institutions, and had an 
average mortality of $0.84 \%$. Eighteen hospitals $(2.7 \%)$ had more than the average of 150 surgeries per year with a patient mortality of $0.17 \%$; those with less than 10 cases had a higher mortality of $2.58 \%$ (4.09 [2.39-7.02]; Figure 9). The patients at hospitals with a volume of 1 to 9 , 10 to 24,25 to 49 , and 50 to 74 surgeries per year had a higher mortality compared with patients at the highest-volume hospitals. Pearson's correlation coefficient for the volume-outcome relationship was $-0.094(\mathrm{p}<0.016)$.

\section{Esophageal cancer surgery}

A total of 24,224 patients underwent esophageal cancer surgery at 493 institutions, and had an average mortality of $1.98 \%$. Twenty-two hospitals $(4.5 \%)$ had more than the average of 40 surgeries per year with a patient mortality of $0.60 \%$; those with less than 5 cases had a mortality of $2.41 \%$ (3.23 [2.02-5.15]; Figure 10). The patients at hospitals with a volume of 1 to 4,5 to 9 , 10 to 14 , and 15 to 19 surgeries per year had a higher mortality compared with the highest-volume hospitals. Pearson's correlation coefficient for the volume-outcome relationship was $-0.082(\mathrm{p}=0.067)$. There was no significant correlation between the hospital volume and the patient mortality in surgery for esophageal cancer surgery.

\section{EB mortality}

Table 2 shows comparison between the crude- and EB- mortality of each procedure regarding the hospital volume and mortality relationship over 5 years. For example, the crude mortality of the total acquired heart disease of the 5-year average was $3.40 \pm 3.80 \%$, and the EB mortality was $3.08 \pm 1.64 \%$. Pearson's correlation coefficient for the volume-outcome relationship was $-0.186(\mathrm{p}=0.0005)$ for crude mortality and $-0.234(\mathrm{p}<0.0001)$ for the EB mortality.

The number of hospitals with "inferior outcomes" evaluated by the EB mortality is shown in 
Figure 11 and Table 3. The Figure shows the relationship between the hospital volume and the EB mortality. The red line shows the average EB mortality for all hospitals over 5 years. If the lower bound of the hospital's EB mortality $95 \% \mathrm{CI}$ is higher than the average EB mortality, the outcome is considered to be "inferior" with a probability of more than $95 \%$. There were 18 hospitals (3.4\%) with inferior outcomes among the lowest volume hospitals (0 to 49) for total acquired heart disease; similarly, there were 8 hospitals (1.5\%) with inferior outcomes among the second-lowest volume hospitals (50 to 99), 1 hospital (0.8\%) among the 100 to 199 volume hospitals, and 1 hospital (0.8\%) with inferior outcomes in the highest volume hospitals. This indicates that the proportion of inferior hospitals was low, and that there were some inferior hospitals in both the lowest- and highest-volume hospitals. There were no inferior outcomes at hospitals for conventional operations such as elective CABG, single-valve surgery, and lung cancer surgery, and there were only a few hospitals with inferior outcomes for the more complex procedures such as surgery for newborns $(1.8 \%)$, infants $(0.8 \%)$ and esophageal cancer $(0.2 \%)$.

\section{DISCUSSION}

\section{Main findings}

In the present report, we reviewed the relationship between the hospital volume and the cardiothoracic surgery outcomes in Japan between 2005 and 2009. Compared with our previous 5-year report (2000-2004) ${ }^{6}$, the total number of cardiothoracic surgeries increased except for that of CABG. Both elective and emergency CABG surgery numbers decreased possibly because of the increasing number of percutaneous coronary interventions particularly with drug-eluting stents. The 30-day mortality decreased in all types of surgery, particularly in surgery for newborns, infants, and esophageal cancer. Considerable outcome improvements in 
congenital heart surgery are because of the recently established staged strategies such as bilateral pulmonary artery banding for hypoplastic left heart syndrome. The number of lung cancer operations is steadily increasing, as is that of hospitals centers for lung cancer operations. The lung cancer surgical mortality and morbidity have been stable and are at an acceptable level. It should be stressed that the average mortality rate has improved to $1.98 \%$ compared with $5.80 \%$ that was previously reported.

There were significant but low inverse correlations between the hospital volume and the 30-day mortality in elective CABG, emergency CABG, single-valve surgery, surgery for type A dissection, and lung cancer surgery. There was no correlation between hospital volume and the 30-day patient mortality in open heart surgery for newborns, surgery for infants, and esophageal cancer surgery. Although some of the lower-volume hospitals had a high patient mortality, most of the low-volume hospitals were associated with low patient mortality.

In the present report, we used EB estimation to adjust the wide variety of mortality particularly in the lower-volume hospitals. There was also a weak but significant inverse correlation between the hospital volume and patient outcome, except in surgery for newborns. However, there was no hospital with inferior outcomes for conventional operations, such as elective $\mathrm{CABG}$, single valve surgery and lung cancer surgery. The ratio of hospital volume to patient outcome in inferior hospitals was very low, even in the more complex procedures such as open heart surgery for newborns, infants, and esophageal cancer surgery. These findings indicate that there is a very weak or no inverse correlation between the hospital volume and patient mortality in cardiothoracic surgery in Japan, and that most of the low-volume hospitals are not associated with inferior outcomes. The lower-volume hospitals' performance should be carefully scrutinized using risk adjustment. 


\section{Comparison with a foreign database}

The Society for Thoracic Surgery (STS) database published data from 774,881 isolated CABG procedures, performed between 2002 and 2006, in adult patients aged 20 to 100 years. The overall unadjusted 30-day mortality was $2.3 \%$. The STS executive summary for 10 years showed that the unadjusted operative patient mortality for isolated CABG was $2.3 \%$ in 2005 and $2.0 \%$ in $2009^{16}$. The annual JATS report showed that the unadjusted 30-day patient mortality for total CABG was $2.0 \%$ in $2005^{9}$ and $1.6 \%$ in $2009^{13}$.

The STS database also published data from 109,759 adult isolated valve surgeries (without concomitant CABG), that were performed between 2002 and $2006{ }^{17}$. There were 67,292 cases of isolated aortic valve replacement (AVR), 21,229 cases of isolated mitral valve replacement (MVR), or 21,238 isolated mitral valve repair (MVRpair). The overall unadjusted 30-day mortality was $3.4 \%$. The unadjusted 30-day patient mortalities for each procedure were $3.2 \%$ for AVR, 5.7\% for MVR, and 1.6\% for MVRpair. The STS executive summary for 10 years showed that the unadjusted operative mortalities in 2005 were $2.9 \%$ for isolated AVR, $5.0 \%$ for AVR+CABG, $5.2 \%$ for isolated MVR, $11.4 \%$ for MVR+CABG, $1.4 \%$ for isolated MVRpair, and $7.0 \%$ for MVRpair+CABG; the unadjusted operative mortalities in 2009 were $3.0 \%$ for isolated AVR, 4.7\% for AVR+CABG, 5.2\% for isolated MVR, 9.7\% for MVR+CABG, $1.3 \%$ for isolated MVRpair, and 5.5\% for MVRpair+CABG. The Japanese annual report, however, included isolated valve surgery with or without concomitant $\mathrm{CABG}^{9}{ }^{13}$. The unadjusted 30-day mortality in 2005 was $2.1 \%$ for AVR, 3.2\% for MVR, and 1.6\% for MVRpair, and in 2009, it was $2.5 \%$ for AVR, 3.8\% for MVR, and $1.4 \%$ for MVRpair. The valve surgery outcomes did not improve both in the US and Japan, which may be due to the expanding surgical indication and the increasing number of high-risk patients.

The STS executive summary reported the congenital heart surgery data summary from 2007 
${ }^{16}$. Between 2007 and 2010, a total of 14,971 newborns underwent congenital heart surgery and the unadjusted in-hospital mortality was $10.1 \%$. Similarly, a total of 25,323 infants underwent congenital heart surgery and the unadjusted in-hospital mortality was $2.9 \%$. In Japan, a total of 2342 newborns underwent congenital heart surgery between 2006 and $2009^{1011} 1213$, and the unadjusted in-hospital mortality was $12.6 \%$. A total of 8482 infants underwent congenital heart surgery during the same period and the in-hospital mortality was $3.7 \%$.

Thirty-day mortalities for lung cancer surgeries in Japan were 0.8\% in 1997 and $0.4 \%$ in 2006, and $2.3 \%$ in 2008 in the US. In esophageal cancer surgery, 30-day mortalities in Japan were $1.2 \%$ in 2007 and $1.2 \%$ in 2008, and in-hospital mortalities were $3.4 \%$ in 2007 and $2.8 \%$ in $2008^{11}{ }^{12}$, which was better than the in-hospital mortality (8.9\%) in the US between 2007 and $2008^{18}$.

\section{More complex vs. less complex procedures}

A number of studies have shown the inverse correlation between the hospital volume and patient mortality ${ }^{19} 18{ }^{20}$. However, the strength of the correlation is different between more complex and less complex procedures 2021422 . CABG is a less complex procedure and is performed more frequently than any other more complex procedures. Compared with other complex, but less frequently performed, procedures, most of the studies reported a weak or no hospital volume-mortality relationship for CABG surgery. However, there were significant hospital volume-mortality relationship in more complex procedures such as aortic root replacement ${ }^{19}$, mitral valve surgery ${ }^{23}$, and pancreatectomy ${ }^{4}$

In the present study, however, there was a very low or no correlation between the hospital volume and outcome in all types of procedures. After adjustment using the EB-method, there was no inferior hospital outcome regarding conventional procedures such as elective CABG, 
single-valve surgery. Even in more complex procedures such as surgery for newborns, there were only a few hospitals with inferior outcomes. These outcomes indicate that lower-volume hospitals are not necessarily associated with high mortality regardless of the complexity of procedures in Japan. For congenital heart surgery, however, there was no correlation between hospital volume and outcome both for newborns and infants, which may be due to relatively wide variety of mortality not only in lower-volume but also higher-volume hospitals. In addition, the small sample size for congenital heart surgery may influence the outcomes.

\section{Low-volume hospitals: are they really inferior?}

The lower-volume hospitals had significantly higher mortality rates as reported by several studies. However, there was a wide residual variability in the outcomes at all hospital volumes. Because of this variation, volume alone may be a poor predictor of an individual hospital's true risk-adjusted mortality rate ${ }^{20}$. There have been important issues to be addressed regarding the outcomes of lower-volume hospitals. Particularly in Japan, where more lower-volume hospitals exist compared with the US or Europe, the issue should be carefully scrutinized. First, the number of operations in "high-volume" hospitals in Japan was different from that of the US. For example, recent report from the STS database defined hospitals with more than 450 CABGs per year as the highest-volume and those less than 100 as the lowest-volume hospitals ${ }^{20}$. In the present report, if the US definition is applied, most of the Japanese hospitals are classified into the lowest-volume hospitals. As shown above, however, CABG outcomes were similar or somewhat better in Japan than in the US. Although cardiovascular surgery programs are different between the US and Japan, the lower-volume hospital performance should be carefully scrutinized. In addition, CABG volumes have decreased both in the US and Japan because of better medical therapy and the increasing use of percutaneous coronary intervention. However, 
overall CABG mortality has continued to decrease despite progressively lower volumes and increasing patient severity. This might reflect both the relatively weaker volume-outcome association for $\mathrm{CABG}$ compared with other procedures and improvements in surgical techniques, anesthesia, and perioperative care.

In the present study, we used the EB method to adjust the variability of low-volume hospitals. Although an inverse correlation between hospital volume and patient mortality existed, there was no or only a few hospitals with inferior outcomes. Furthermore, there were some hospitals with inferior outcomes in the lowest-volume and also in the moderate-volume hospitals in total acquired heart disease. To evaluate the hospital-volume-outcome relationships more accurately, risk adjustment according to the patients' preoperative risk factors, such as with propensity matching, may be essential ${ }^{24}$.

\section{CONCLUSIONS}

There is weak or no inverse correlation between the hospital volume and the 30-day mortality in cardiothoracic surgery in Japan. Most of the low-volume hospitals were not associated with inferior outcomes. The performance of the lower-volume hospitals should be carefully scrutinized using risk adjustment.

\section{ACKNOWLEDGEMENTS}

We thank Ms. Etsuko Yamakoshi (Statcom Co. Ltd., Tokyo, JAPAN) for statistical analyses of the present study. 


\section{FIGURE LEGENDS}

\section{Figures 1-10}

Scatter diagram for each procedure showing the 30-day mortality rate according to the number of operations. The corresponding table shows the actual number of operations and the mortality rates.

r: Pearson's correlation coefficient

SD: standard deviation

$\mathrm{CV}$ : coefficient of variance

LCL: lower confidence limit

UCL: upper confidence limit;

*statistically significant

\section{Figure 11}

The relationship between the hospital volume and EB mortality. The red line shows the 5-year average EB mortality of all hospitals. If the lower limit of the EB mortality 95\% confidence interval for each hospital is higher than the average EB mortality, the outcome is considered to have a greater than $95 \%$ chance of being inferior.

Blue circles: Hospitals with outcomes of non-inferiority

Red squares: Hospitals with outcomes of inferiority

Black bars: Lower $95 \%$ confidence interval

Upper panel: number of hospitals with inferior outcomes in each stratification (1-49, 50-99, 100-199, and 200-, respectively). 


\section{REFERENCES}

1. Luft HS, Bunker JP, Enthoven AC. Should operations be regionalized - empirical relation between surgical volume and mortality. New Engl $J$ Med. 1979;301:1364-1369.

2. Dudley RA, Johansen KL, Brand R, Rennie DJ, Milstein A. Selective referral to high-volume hospitals - estimating potentially avoidable deaths. J Am Med Assoc. 2000;283:1159-1166.

3. Birkmeyer JD, Siewers AE, Finlayson EV, Stukel TA, Lucas FL, Batista I, Welch HG, Wennberg DE. Hospital volume and surgical mortality in the United States. New Engl J Med. 2002;346:1128-1137.

4. Shahian DM, Normand SLT. The volume-outcome relationship: From luft to leapfrog. Annal Thoracic Surg. 2003;75:1048-1058.

5. Nishida H, Yoshida E. Suggestions from non-pandering govermental health care policy groups: Across the board 30\% cut of surgeon's fee according to number of operation -pandering fool and disguised healthcare cost-cutting policy under fiscal crisis-. Cardiovasc Med Surg. 2005;7:417-429.

6. Kazui T, Osada H, Fujita H. An attempt to analyze the relation between hospital surgical volume and clinical outcome. Gen Thoracic Cardiovasc Surg. 2007:55:483-492.

7. Osada H, Yamakoshi E. Hospital volume and surgical outcomes of lung cancer in Japan. Gen Thoracic Cardiovasc Surg. 2007;55:360-365.

8. Clayton D, Kaldor J. Empirical Bayes estimates of age-standardized relative risks for use in disease mapping. Biometrics. 1987;43:671-681.

9. Ueda Y, Osada H, Osugi H. Thoracic and cardiovascular surgery in Japan during 2005. Annual report by the Japanese Association for Thoracic Surgery. Gen Thoracic Cardiovasc Surg. 2007;55:377-399.

10. Ueda Y, Fujii Y, Udagawa H. Thoracic and cardiovascular surgery in Japan during 2006: Annual report by the Japanese Association for Thoracic Surgery. Gen Thoracic Cardiovasc Surg. 2008;56:365-388.

11. Ueda Y, Fujii Y, Kuwano H. Thoracic and cardiovascular surgery in Japan during 2007. Annual report by the Japanese Association for Thoracic Surgery. Gen Thoracic Cardiovasc Surg. 2009;57:488-513.

12. Sakata R, Fujii Y, Kuwano H. Thoracic and cardiovascular surgery in Japan during 2008: Annual report by the Japanese Association for Thoracic Surgery. Gen Thoracic Cardiovasc Surg. 2010;58:356-383.

13. Sakata R, Fujii Y, Kuwano H. Thoracic and cardiovascular surgery in Japan during 
2009. Gen Thoracic Cardiovasc Surg. 2011;59:636-667.

14. Liang KY, Zeger SL. Longitudinal data-analysis using generalized linear-models. Biometrika. 1986;73:13-22.

15. Shahian DM, O'Brien SM, Filardo G, Ferraris VA, Haan CK, Rich JB, Normand SL, DeLong ER, Shewan CM, Dokholyan RS, Peterson ED, Edwards FH, Anderson RP. The Society of Thoracic Surgeons 2008 cardiac surgery risk models: Part 1 - coronary artery bypass grafting surgery. Ann Thoracic Surg. 2009;88:S2-22.

16. STS national database executive summaries. 2011.

17. O'Brien SM, Shahian DM, Filardo G, Ferraris VA, Haan CK, Rich JB, Normand S-LT, DeLong ER, Shewan CM, Dokholyan RS. The Society of Thoracic Surgeons 2008 cardiac surgery risk models: Part 2 - isolated valve surgery. Ann Thoracic Surg. 2009;88:S23-S42.

18. Finks JF, Osborne NH, Birkmeyer JD. Trends in hospital volume and operative moratlity for high-risk surgery. New Engl J Med. 2011;364:2128-2137.

19. Hughes GC, Zhao Y, Rankin JS, Scarborough JE, O'Brien S, Bavaria JE, Wolfe WG, Gaca JG, Gammie JS, Shahian DM, Smith PK. Effects of institutional volumes on operative outcomes for aortic root replacement in North America. $J$ Thoracic Cardiovasc Surg. 2012.

20. Shahian DM, O'Brien SM, Normand SL, Peterson ED, Edwards FH. Association of hospital coronary artery bypass volume with processes of care, mortality, morbidity, and the Society of Thoracic Surgeons composite quality score. J Thoracic Cardiovasc Surg. 2010;139:273-282.

21. Peterson ED, Coombs LP, DeLong ER, Haan CK, Ferguson TB. Procedural volume as a marker of quality for CABG surgery. J Am Med Assoc. 2004;291:195-201.

22. Shahian DM, Normand SLT. Low-volume coronary artery bypass surgery: Measuring and optimizing performance. $J$ Thorac Cardiovasc Surg. 2008;135:1202-1209.

23. Gammie JS, O'Brien SM, Griffith BP, Ferguson TB, Peterson ED. Influence of hospital procedural volume on care process and mortality for patients undergoing elective surgery for mitral regurgitation. Circulation. 2007;115:881-887.

24. Kurlansky PA, Argenziano M, Dunton R, Lancey R, Nast E, Stewart A, Williams T, Zapolanski A, Chang H, Tingley J, Smith CR. Quality, not volume, determines outcome of coronary artery bypass surgery in a university-based community hospital network. J Thoracic Cardiovasc Surg. 2012;143:287-293.e281. 


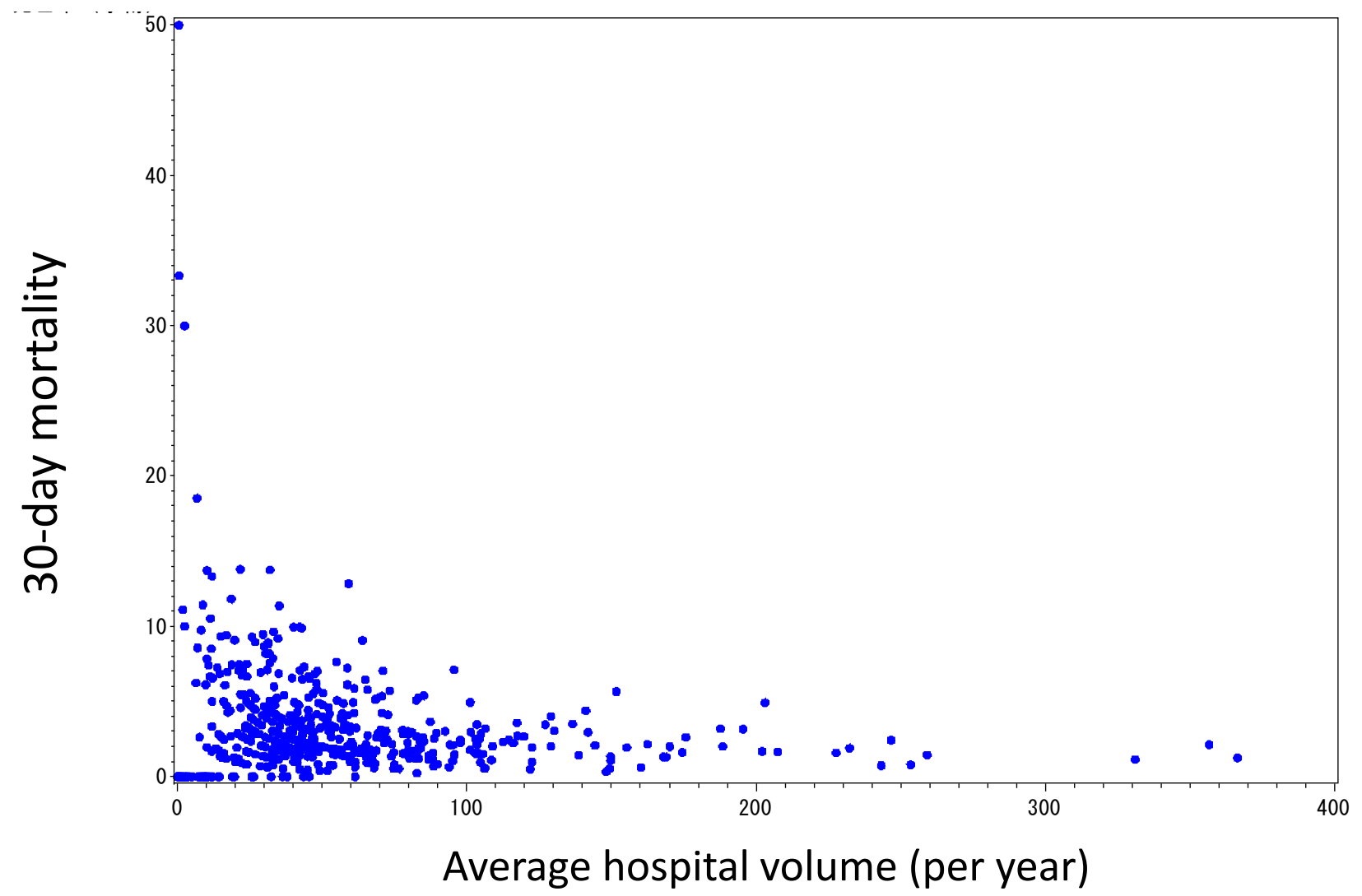

\begin{tabular}{|c|c|c|c|c|c|c|c|c|c|}
\hline & \multirow[b]{2}{*}{ Hospitals } & \multirow[b]{2}{*}{ Patients } & \multicolumn{3}{|c|}{ Mortality (\%) } & \multirow{2}{*}{$\begin{array}{l}\text { Odds } \\
\text { ratio }\end{array}$} & \multirow{2}{*}{$\begin{array}{l}95 \% \\
\text { LCL }\end{array}$} & \multirow{2}{*}{$\begin{array}{l}95 \% \\
\text { UCL } \\
\end{array}$} & \multirow{2}{*}{$\begin{array}{c}\mathrm{r} \\
\mathrm{p} \text {-value } \\
\end{array}$} \\
\hline & & & Mean & S.D. & C.V. & & & & \\
\hline $1: 1-24$ & 125 & 8398 & 4.45 & 6.62 & 148.7 & $1.90 *$ & 1.52 & 2.39 & \multirow{5}{*}{$\begin{array}{c}-0.186 \\
p<0.001\end{array}$} \\
\hline 2: $25-49$ & 187 & 33885 & 3.61 & 2.52 & 69.7 & $1.76^{*}$ & 1.48 & 2.09 & \\
\hline $3: 50-74$ & 101 & 30778 & 3.00 & 2.07 & 69.0 & $1.46^{*}$ & 1.20 & 1.78 & \\
\hline 4: 75-99 & 44 & 18566 & 2.26 & 1.40 & 61.8 & 1.09 & 0.86 & 1.38 & \\
\hline 5: 100- & 65 & 49554 & 2.15 & 1.14 & 53.1 & 1.00 & - & - & \\
\hline ALL & 522 & 141181 & 3.40 & 3.80 & 111.8 & & & & \\
\hline
\end{tabular}




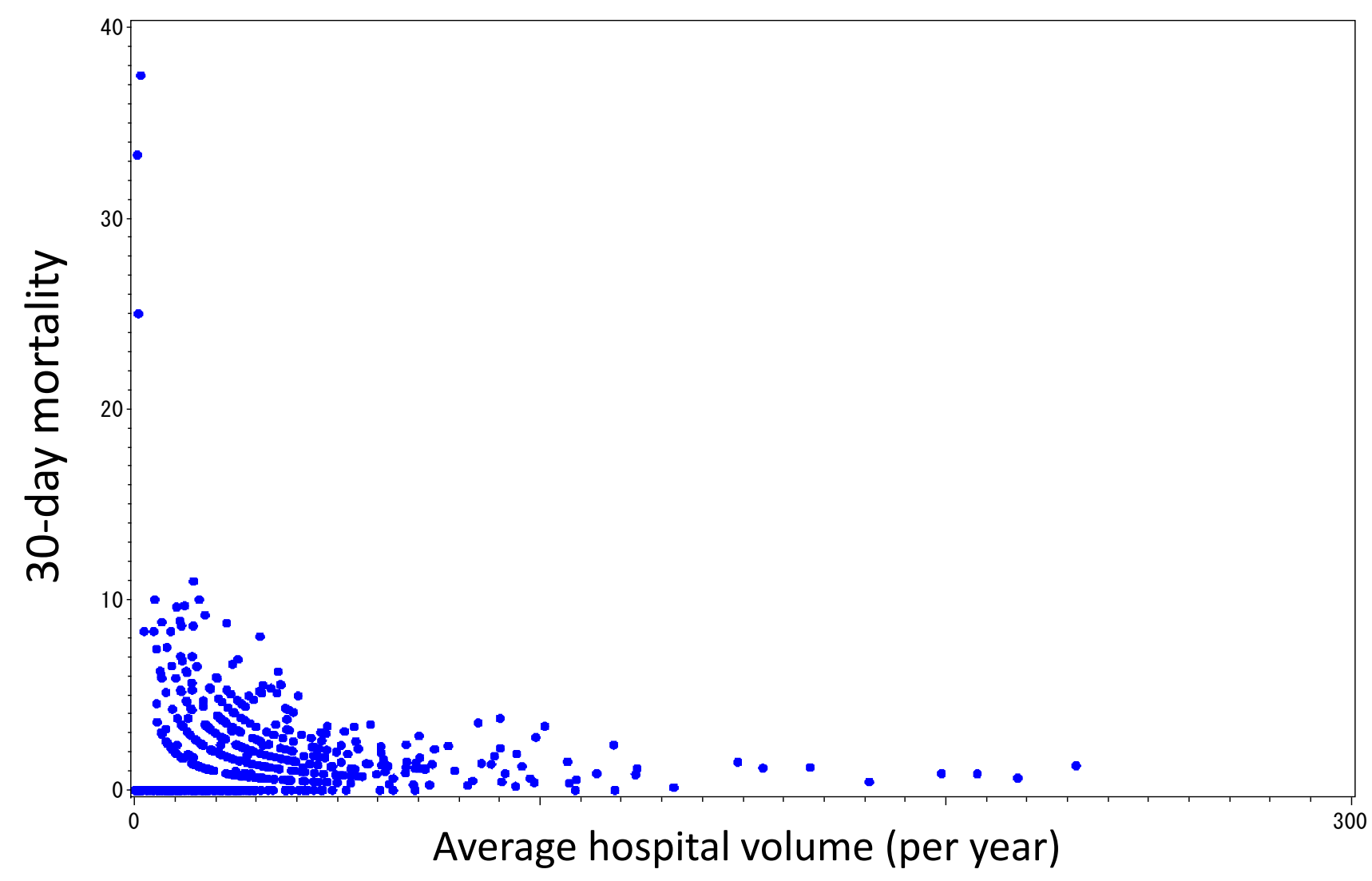

\begin{tabular}{|c|c|c|c|c|c|c|c|c|c|}
\hline & \multirow[b]{2}{*}{ Hospitals } & \multirow[b]{2}{*}{ Patients } & \multicolumn{3}{|c|}{ Mortality (\%) } & \multirow{2}{*}{$\begin{array}{c}\text { Odds } \\
\text { ratio } \\
\end{array}$} & \multirow{2}{*}{$\begin{array}{l}95 \% \\
\text { LCL } \\
\end{array}$} & \multirow{2}{*}{$\begin{array}{l}95 \% \\
\text { UCL } \\
\end{array}$} & \multirow{2}{*}{$\begin{array}{c}\mathrm{r} \\
\mathrm{p} \text {-value } \\
\end{array}$} \\
\hline & & & Mean & S.D. & C.V. & & & & \\
\hline $1: 1-24$ & 245 & 16622 & 2.72 & 4.21 & 154.9 & $2.52 *$ & 1.83 & 3.48 & \multirow{5}{*}{$\begin{array}{c}-0.168 \\
p<0.001\end{array}$} \\
\hline 2: $25-49$ & 183 & 31583 & 1.83 & 1.57 & 85.8 & $1.81 *$ & 1.31 & 2.49 & \\
\hline 3: 50-74 & 53 & 16004 & 1.28 & 0.84 & 65.7 & 1.28 & 0.91 & 1.80 & \\
\hline 4: 75-99 & 18 & 7954 & 1.48 & 1.10 & 74.1 & 1.47 & 0.94 & 2.32 & \\
\hline 5: $100-$ & 19 & 13437 & 1.00 & 0.81 & 81.1 & 1.00 & - & - & \\
\hline ALL & 518 & 85600 & 2.15 & 3.11 & 144.8 & & & & \\
\hline
\end{tabular}


Figure 3

\section{Elective CABG}

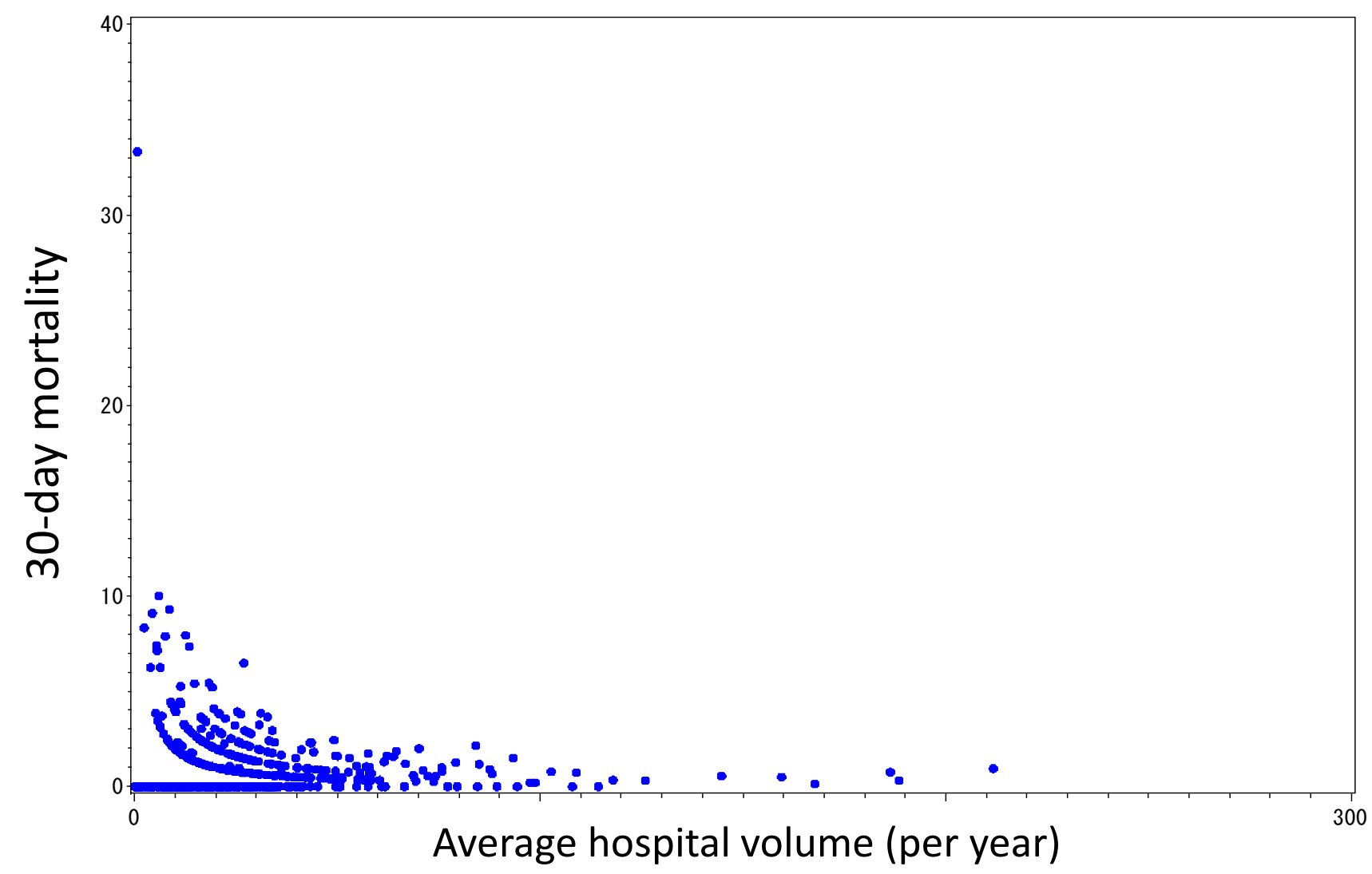

\begin{tabular}{|c|c|c|c|c|c|c|c|c|c|}
\hline & \multirow[b]{2}{*}{ Hospitals } & \multirow[b]{2}{*}{ Patients } & \multicolumn{3}{|c|}{ Mortality (\%) } & \multirow{2}{*}{$\begin{array}{c}\text { Odds } \\
\text { ratio } \\
\end{array}$} & \multirow{2}{*}{$\begin{array}{l}95 \% \\
\text { LCL }\end{array}$} & \multirow{2}{*}{$\begin{array}{l}95 \% \\
\text { UCL } \\
\end{array}$} & \multirow{2}{*}{$\begin{array}{c}\mathrm{r} \\
\mathrm{p} \text {-value } \\
\end{array}$} \\
\hline & & & Mean & S.D. & C.V. & & & & \\
\hline 1: $1-24$ & 294 & 19579 & 1.35 & 2.65 & 195.6 & $2.51 *$ & 1.69 & 3.73 & \multirow{5}{*}{$\begin{array}{c}-0.133 \\
p=0.002\end{array}$} \\
\hline 2: 25-49 & 155 & 26142 & 0.91 & 1.02 & 112.6 & $1.80 *$ & 1.20 & 2.69 & \\
\hline $3: 50-74$ & 42 & 12505 & 0.69 & 0.57 & 83.2 & 1.43 & 0.92 & 2.23 & \\
\hline 4: 75-99 & 15 & 6301 & 0.66 & 0.67 & 102.1 & 1.33 & 0.71 & 2.50 & \\
\hline 5: 100- & 12 & 8410 & 0.45 & 0.31 & 69.8 & 1.00 & - & - & \\
\hline ALL & 518 & 72937 & 1.12 & 2.10 & 186.4 & & & & \\
\hline
\end{tabular}




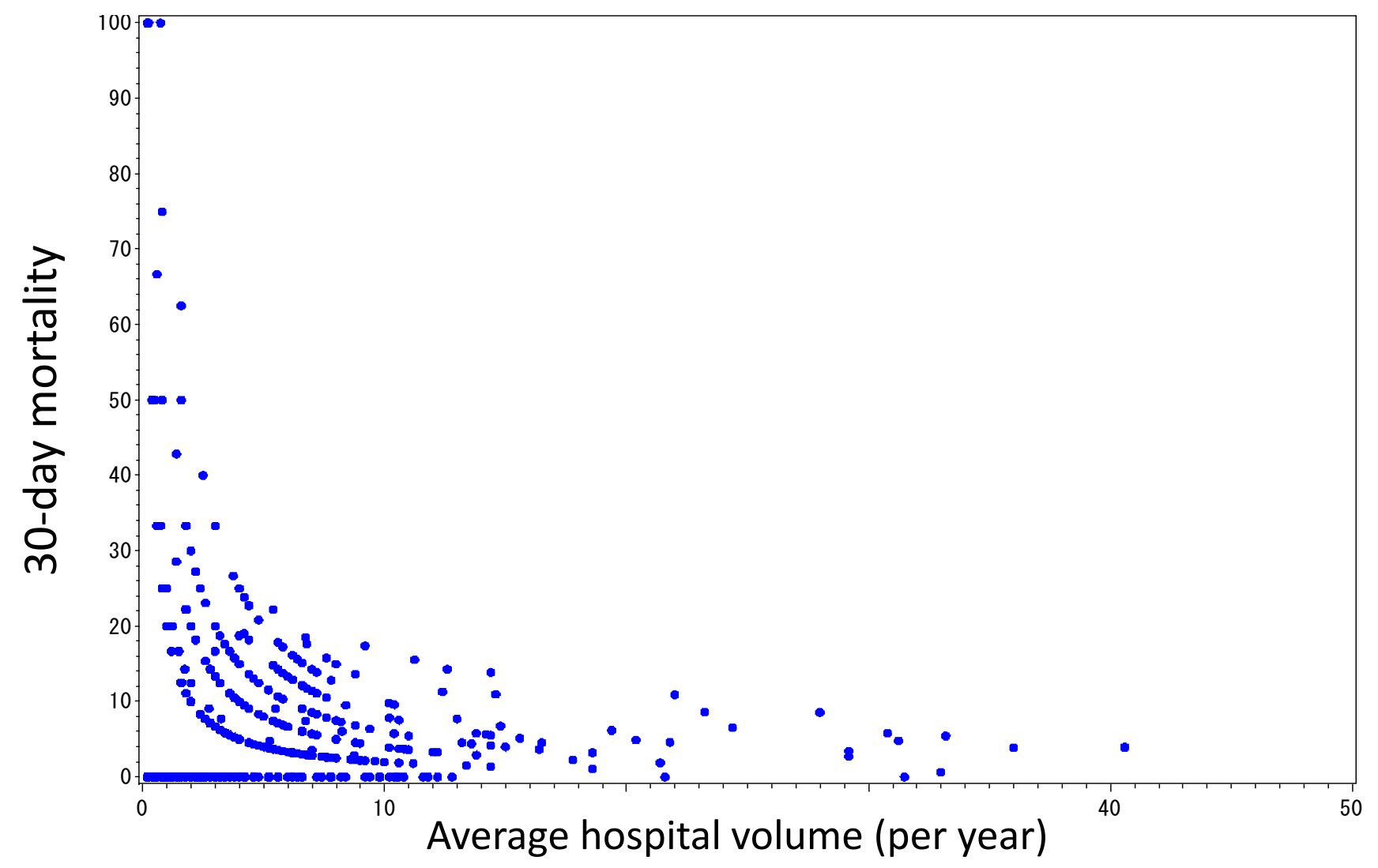

\begin{tabular}{|c|c|c|c|c|c|c|c|c|c|}
\hline & \multirow[b]{2}{*}{ Hospitals } & \multirow[b]{2}{*}{ Patients } & \multicolumn{3}{|c|}{ Mortality (\%) } & \multirow{2}{*}{$\begin{array}{l}\text { Odds } \\
\text { ratio }\end{array}$} & \multirow{2}{*}{$\begin{array}{l}95 \% \\
\text { LCL }\end{array}$} & \multirow{2}{*}{$\begin{array}{l}95 \% \\
\text { UCL } \\
\end{array}$} & \multirow{2}{*}{$\begin{array}{c}r \\
\text { p-value }\end{array}$} \\
\hline & & & Mean & S.D. & C.V. & & & & \\
\hline $1: 1-4$ & 293 & 3123 & 10.50 & 15.94 & 151.9 & $2.24 *$ & 1.57 & 3.19 & \multirow{5}{*}{$\begin{array}{c}-0.169 \\
p<0.001\end{array}$} \\
\hline $2: 5-9$ & 124 & 4184 & 6.59 & 5.43 & 82.4 & $1.50 *$ & 1.05 & 2.14 & \\
\hline 3: $10-14$ & 40 & 2381 & 4.74 & 4.29 & 90.5 & 1.09 & 0.71 & 1.68 & \\
\hline 4:15-19 & 8 & 673 & 3.76 & 1.61 & 42.9 & 0.79 & 0.51 & 1.22 & \\
\hline 5:20- & 17 & 2302 & 4.51 & 3.05 & 67.7 & 1.00 & - & - & \\
\hline ALL & 482 & 12663 & 8.69 & 13.01 & 149.6 & & & & \\
\hline
\end{tabular}


Figure 5

Single valve surgery

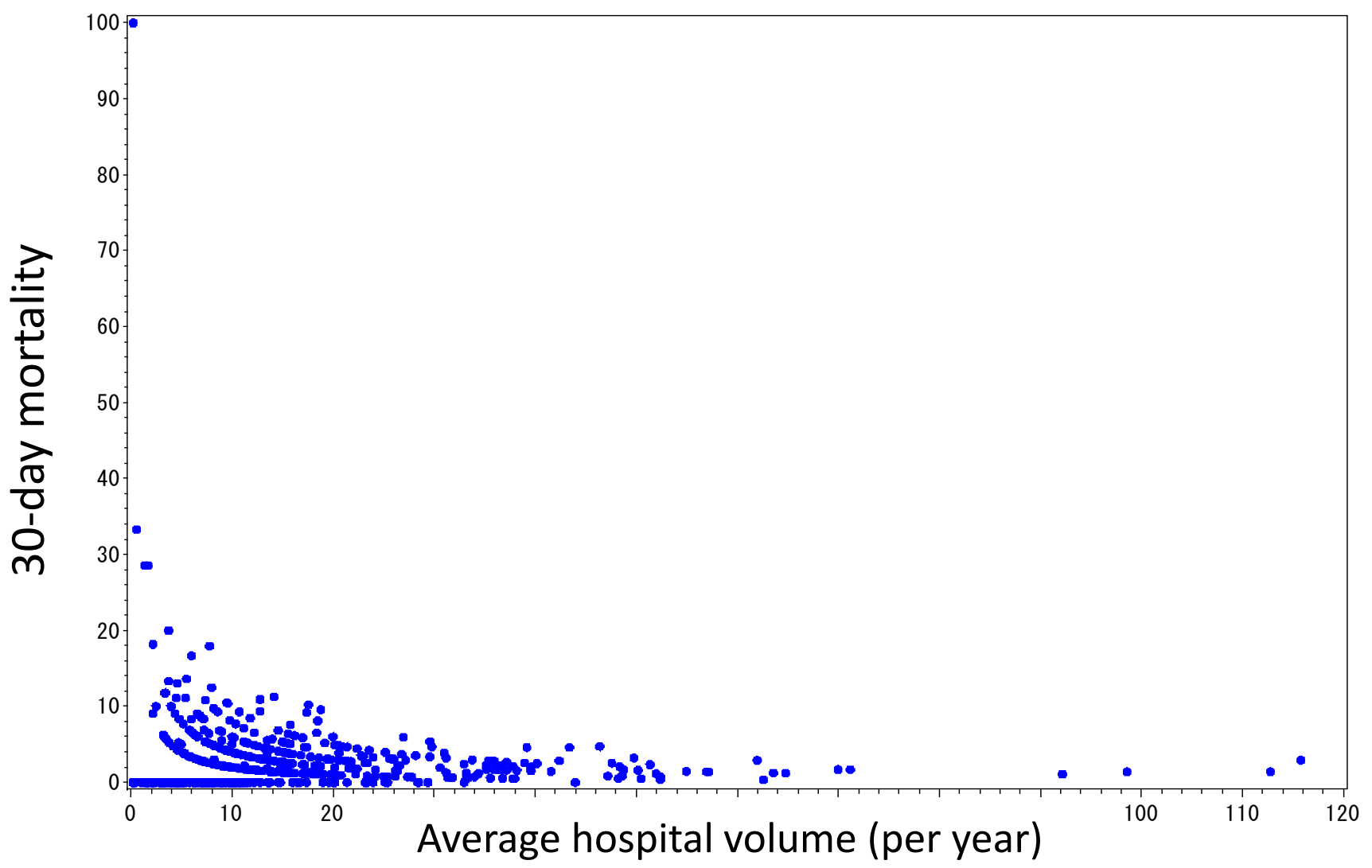

\begin{tabular}{|c|c|c|c|c|c|c|c|c|c|}
\hline & \multirow[b]{2}{*}{ Hospitals } & \multirow[b]{2}{*}{ Patients } & \multicolumn{3}{|c|}{ Mortality (\%) } & \multirow{2}{*}{$\begin{array}{c}\text { Odds } \\
\text { ratio } \\
\end{array}$} & \multirow{2}{*}{$\begin{array}{l}95 \% \\
\text { LCL } \\
\end{array}$} & \multirow{2}{*}{$\begin{array}{l}95 \% \\
\text { UCL } \\
\end{array}$} & \multirow{2}{*}{$\begin{array}{c}\mathrm{r} \\
\mathrm{p} \text {-value } \\
\end{array}$} \\
\hline & & & Mean & S.D. & C.V. & & & & \\
\hline $1: 1-14$ & 310 & 11958 & 3.80 & 7.12 & 187.4 & $2.01 *$ & 1.45 & 2.78 & -0.150 \\
\hline $2: 15-29$ & 133 & 13451 & 2.65 & 2.16 & 81.3 & $1.56 *$ & 1.12 & 2.18 & $\mathrm{p}<0.001$ \\
\hline $3: 30-44$ & 44 & 7792 & 1.77 & 1.12 & 63.4 & 1.08 & 0.76 & 1.54 & \\
\hline 4: 45-59 & 17 & 4217 & 1.61 & 1.12 & 69.7 & 0.97 & 0.63 & 1.50 & \\
\hline $5: 60-$ & 10 & 4068 & 1.60 & 0.80 & 49.9 & 1.00 & - & - & \\
\hline ALL & 514 & 41486 & 3.21 & 5.70 & 177.4 & & & & \\
\hline
\end{tabular}


Acute type-A dissection surgery

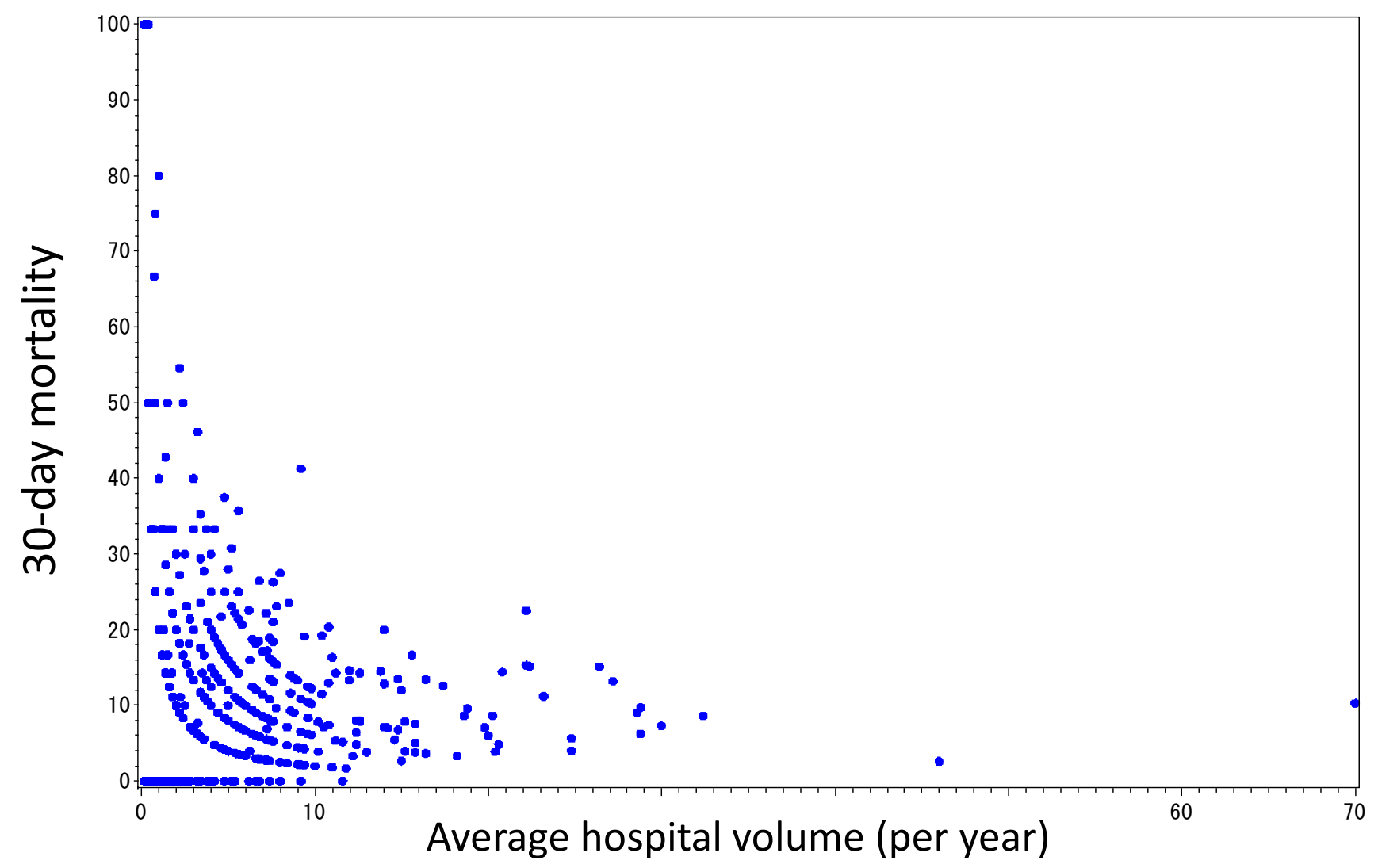

\begin{tabular}{|c|c|c|c|c|c|c|c|c|c|}
\hline & \multirow[b]{2}{*}{ Hospitals } & \multirow[b]{2}{*}{ Patients } & \multicolumn{3}{|c|}{ Mortality (\%) } & \multirow{2}{*}{$\begin{array}{c}\text { Odds } \\
\text { ratio } \\
\end{array}$} & \multirow{2}{*}{$\begin{array}{l}95 \% \\
\text { LCL } \\
\end{array}$} & \multirow{2}{*}{$\begin{array}{l}95 \% \\
\text { UCL } \\
\end{array}$} & \multirow{2}{*}{$\begin{array}{c}\mathrm{r} \\
\mathrm{p} \text {-value } \\
\end{array}$} \\
\hline & & & Mean & S.D. & C.V. & & & & \\
\hline $1: 1-4$ & 266 & 3051 & 16.07 & 19.28 & 120.0 & $1.48 *$ & 1.14 & 1.93 & \multirow{5}{*}{$\begin{array}{c}-0.176 \\
\mathrm{p}<0.001\end{array}$} \\
\hline $2: 5-9$ & 140 & 4891 & 10.62 & 7.99 & 75.2 & 1.13 & 0.86 & 1.48 & \\
\hline 3: $10-14$ & 36 & 2129 & 9.01 & 5.38 & 59.8 & 0.97 & 0.70 & 1.32 & \\
\hline 4: $15-19$ & 15 & 1245 & 7.86 & 4.29 & 54.6 & 0.84 & 0.58 & 1.22 & \\
\hline 5: $20-$ & 20 & 2779 & 9.70 & 5.04 & 51.9 & 1.00 & - & - & \\
\hline ALL & 477 & 14095 & 13.41 & 15.45 & 115.2 & & & & \\
\hline
\end{tabular}


Open heart surgery for the newborns

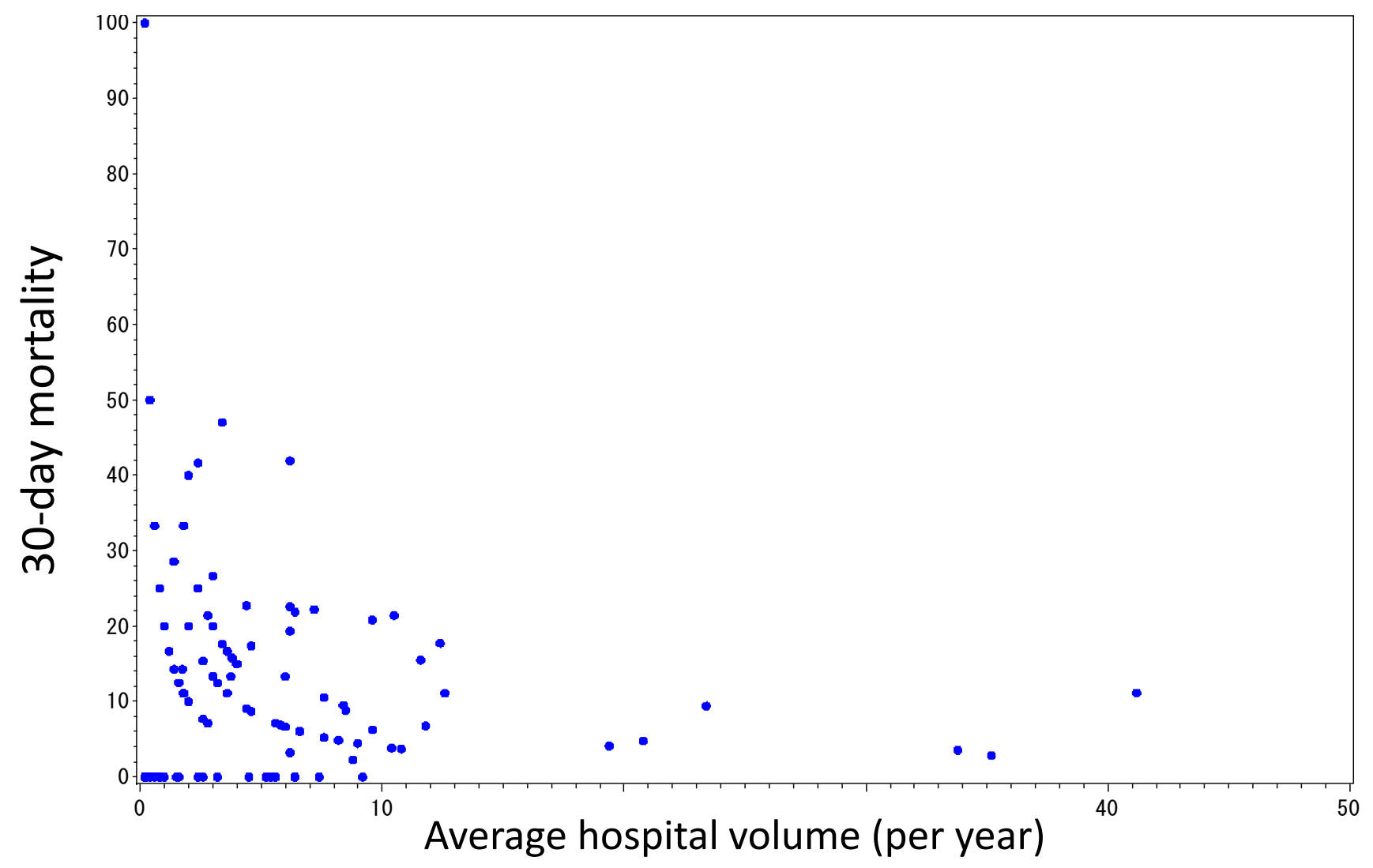

\begin{tabular}{|c|c|c|c|c|c|c|c|c|c|}
\hline & \multirow[b]{2}{*}{ Hospitals } & \multirow[b]{2}{*}{ Patients } & \multicolumn{3}{|c|}{ Mortality (\%) } & \multirow{2}{*}{$\begin{array}{l}\text { Odds } \\
\text { ratio }\end{array}$} & \multirow{2}{*}{$\begin{array}{l}95 \% \\
\text { LCL }\end{array}$} & \multirow{2}{*}{$\begin{array}{l}95 \% \\
\text { UCL }\end{array}$} & \multirow{2}{*}{$\begin{array}{c}\mathrm{r} \\
\mathrm{p}-\mathrm{value}\end{array}$} \\
\hline & & & Mean & S.D. & C.V. & & & & \\
\hline $1: 1-4$ & 65 & 618 & 13.52 & 16.80 & 124.3 & $2.46 *$ & 1.45 & 4.17 & \multirow{4}{*}{$\begin{array}{c}-0.108 \\
p=0.273\end{array}$} \\
\hline $2: 5-9$ & 27 & 948 & 9.04 & 10.01 & 110.7 & 1.42 & 0.73 & 2.76 & \\
\hline 3: $10-19$ & 8 & 487 & 10.53 & 6.99 & 66.4 & 1.68 & 0.85 & 3.31 & \\
\hline $4: 20-$ & 5 & 772 & 6.35 & 3.71 & 58.4 & 1.00 & - & - & \\
\hline ALL & 105 & 2825 & 11.80 & 14.42 & 122.2 & & & & \\
\hline
\end{tabular}




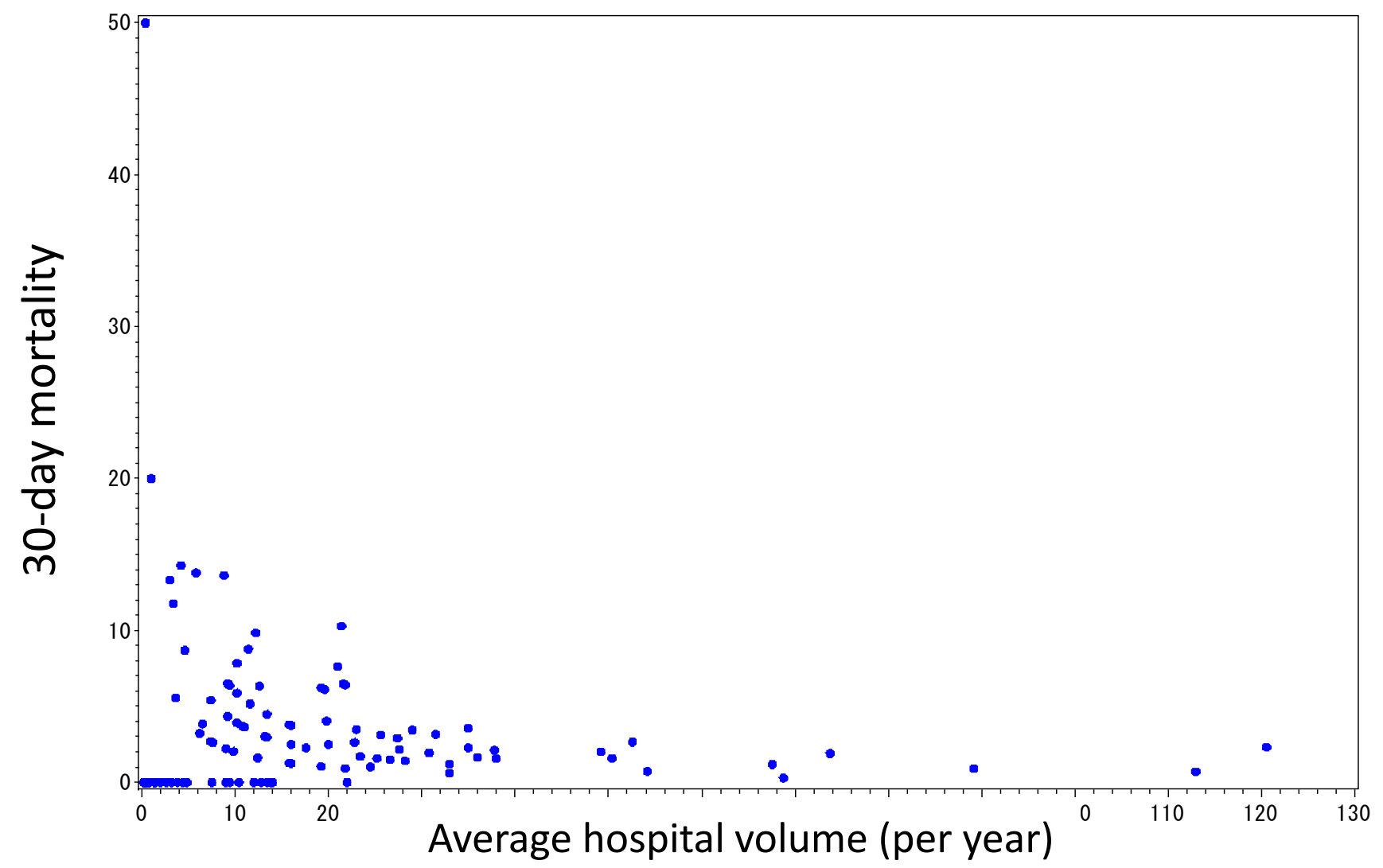

\begin{tabular}{|c|c|c|c|c|c|c|c|c|c|}
\hline & \multirow[b]{2}{*}{ Hospitals } & \multirow[b]{2}{*}{ Patients } & \multicolumn{3}{|c|}{ Mortality (\%) } & \multirow{2}{*}{$\begin{array}{l}\text { Odds } \\
\text { ratio }\end{array}$} & \multirow{2}{*}{$\begin{array}{l}95 \% \\
\text { LCL }\end{array}$} & \multirow{2}{*}{$\begin{array}{l}95 \% \\
\text { UCL } \\
\end{array}$} & \multirow{2}{*}{$\begin{array}{c}\mathrm{r} \\
\mathrm{p} \text {-value } \\
\end{array}$} \\
\hline & & & Mean & S.D. & C.V. & & & & \\
\hline 1: $1-9$ & 33 & 294 & 5.26 & 12.64 & 240.2 & $3.24 *$ & 1.53 & "6.85 & \multirow{4}{*}{$\begin{array}{c}-0.151 \\
p=0.108\end{array}$} \\
\hline 2: $10-19$ & 45 & 2654 & 3.75 & 3.32 & 88.5 & $2.67 *$ & 1.69 & 4.22 & \\
\hline 3: $20-49$ & 28 & 3850 & 2.84 & 2.29 & 80.6 & $1.95 *$ & 1.22 & 3.13 & \\
\hline 4: $50-$ & 9 & 3451 & 1.36 & 0.80 & 58.8 & 1.00 & - & - & \\
\hline ALL & 115 & 10249 & 3.78 & 7.19 & 190.4 & & & & \\
\hline
\end{tabular}


Figure 9

Lung cancer surgery

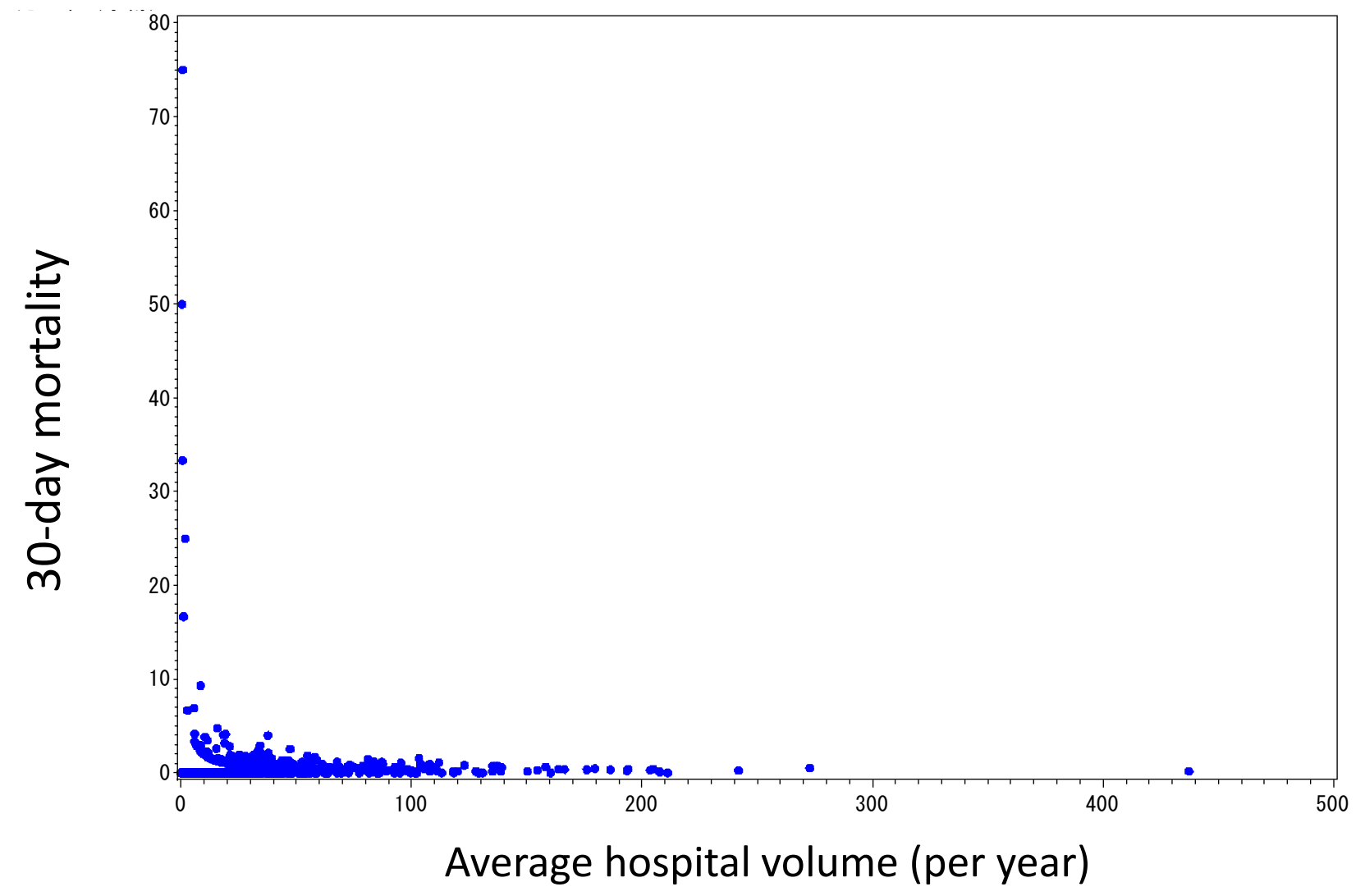

\begin{tabular}{|c|c|c|c|c|c|c|c|c|c|}
\hline & \multirow[b]{2}{*}{ Hospitals } & \multirow[b]{2}{*}{ Patients } & \multicolumn{3}{|c|}{ Mortality (\%) } & \multirow{2}{*}{$\begin{array}{l}\text { Odds } \\
\text { ratio }\end{array}$} & \multirow{2}{*}{$\begin{array}{l}95 \% \\
\text { LCL }\end{array}$} & \multirow{2}{*}{$\begin{array}{l}95 \% \\
\text { UCL }\end{array}$} & \multirow{2}{*}{$\begin{array}{c}\text { r } \\
\text { p-value }\end{array}$} \\
\hline & & & Mean & S.D. & C.V. & & & & \\
\hline $1: 1-9$ & 109 & 2555 & 2.58 & 9.64 & 374.1 & $4.09 *$ & 2.39 & 7.02 & \multirow{7}{*}{$\begin{array}{c}-0.094 \\
p=0.016\end{array}$} \\
\hline $2: 10-24$ & 178 & 14023 & 0.53 & 0.93 & 177.5 & $1.79 *$ & 1.24 & 2.60 & \\
\hline 3: $25-49$ & 175 & 30711 & 0.53 & 0.69 & 128.9 & $1.85 *$ & 1.33 & 2.56 & \\
\hline 4: $50-74$ & 90 & 26448 & 0.42 & 0.42 & 100.7 & $1.49 *$ & 1.07 & 2.09 & \\
\hline 5: 75-99 & 47 & 19580 & 0.40 & 0.34 & 86.6 & 1.38 & 0.96 & 2.00 & \\
\hline 6: $100-149$ & 30 & 17372 & 0.43 & 0.40 & 94.1 & 1.52 & 1.00 & 2.30 & \\
\hline 7: 150- & 18 & 18159 & 0.29 & 0.17 & 58.2 & 1.00 & - & - & \\
\hline ALL & 647 & 128848 & 0.84 & 4.07 & 485.5 & & & & \\
\hline
\end{tabular}




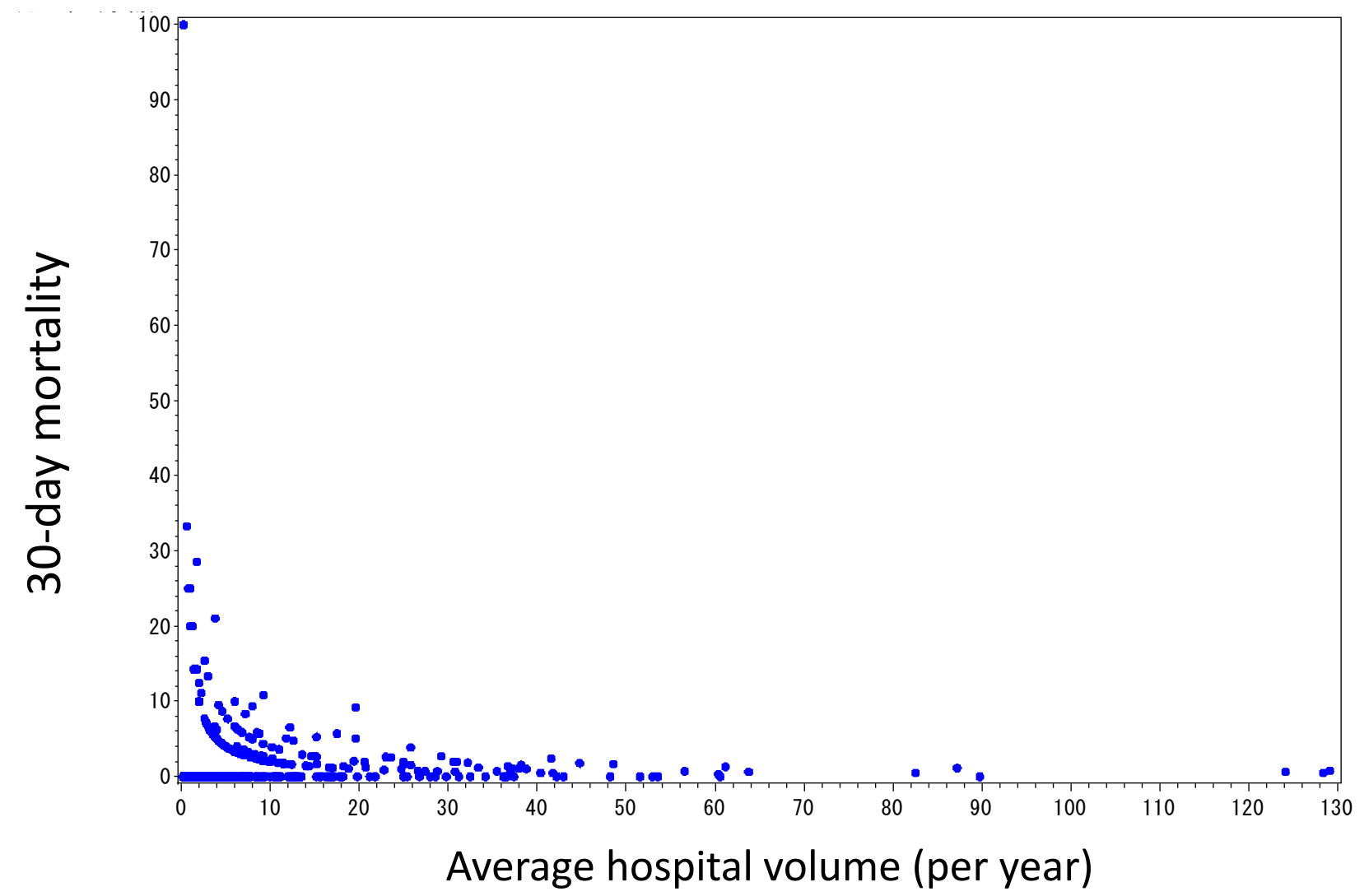

\begin{tabular}{|c|c|c|c|c|c|c|c|c|c|}
\hline & \multirow[b]{2}{*}{ Hospitals } & \multirow[b]{2}{*}{ Patients } & \multicolumn{3}{|c|}{ Mortality (\%) } & \multirow{2}{*}{$\begin{array}{l}\text { Odds } \\
\text { ratio } \\
\end{array}$} & \multirow{2}{*}{$\begin{array}{l}95 \% \\
\text { LCL } \\
\end{array}$} & \multirow{2}{*}{$\begin{array}{l}95 \% \\
\text { UCL } \\
\end{array}$} & \multirow{2}{*}{$\begin{array}{c}\mathrm{r} \\
\mathrm{p} \text {-value }\end{array}$} \\
\hline & & & Mean & S.D. & C.V. & & & & \\
\hline $1: 1-4$ & 263 & 3116 & 2.41 & 8.12 & 336.8 & $3.23 *$ & 2.02 & 5.15 & \multirow{7}{*}{$\begin{array}{c}-0.082 \\
p=0.067\end{array}$} \\
\hline 2: 5-9 & 95 & 3131 & 2.03 & 2.66 & 131.0 & $3.59 *$ & 2.28 & 5.65 & \\
\hline $3: 10-14$ & 45 & 2648 & 1.30 & 1.66 & 127.2 & $2.31 *$ & 1.37 & 3.90 & \\
\hline 4: $15-19$ & 25 & 2071 & 1.56 & 2.38 & 152.5 & $2.82 *$ & 1.37 & 5.81 & \\
\hline 5: $20-29$ & 24 & 2914 & 1.01 & 1.12 & 111.9 & 1.65 & 0.91 & 3.00 & \\
\hline $6: 30-39$ & 19 & 3215 & 0.79 & 0.73 & 92.9 & 1.33 & 0.77 & 2.29 & \\
\hline $7: 40-$ & 22 & 7129 & 0.60 & 0.68 & 111.9 & 1.00 & - & - & \\
\hline
\end{tabular}


Figure 11

Total Acquired Heart Disease

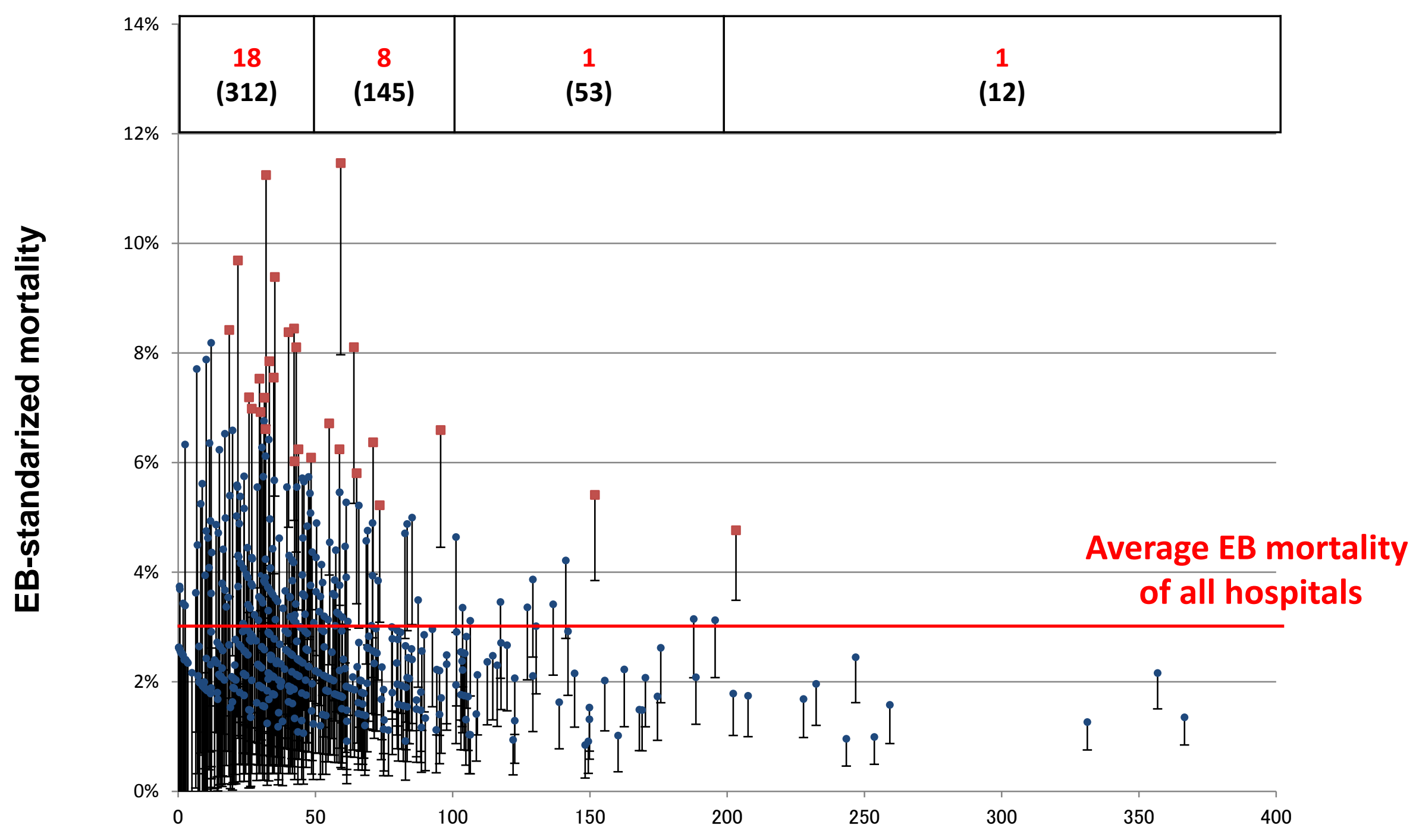

Average hospital volume (per year) 
Table 1. Number of patients, hospitals, and mean 30-day mortality (2005 -2009 vs. 2000 -2004)

\begin{tabular}{|c|c|c|c|c|c|c|}
\hline \multirow[b]{2}{*}{ Procedures } & \multicolumn{3}{|c|}{ 2005-2009 } & \multicolumn{3}{|c|}{$2000-2004 * *$} \\
\hline & Patients & Hospitals & $\begin{array}{l}\text { Mean 30-day } \\
\text { mortality (\%) }\end{array}$ & Patients & Hospitals & $\begin{array}{l}\text { Mean 30-day } \\
\text { mortality (\%) }\end{array}$ \\
\hline Surgery for acquired heart disease* & 141181 & 522 & 3.40 & 153616 & 556 & 3.90 \\
\hline Elective + emergency CABG & 85600 & 518 & 2.15 & 101321 & 551 & 2.80 \\
\hline Elective CABG & 72937 & 518 & 1.12 & 84468 & 483 & 1.50 \\
\hline Emergency CABG & 12663 & 482 & 8.69 & 13900 & 509 & 10.90 \\
\hline Single-valve surgery & 41486 & 514 & 3.21 & 40619 & 485 & 3.70 \\
\hline Surgery for acute type A dissection & 14095 & 477 & 13.41 & 10097 & 439 & 16.30 \\
\hline Open heart surgery for newbones & 2825 & 105 & 11.80 & 2611 & 131 & 19.80 \\
\hline Open heart surgery for infants & 10249 & 115 & 3.78 & 8586 & 135 & 5.90 \\
\hline Lung cancer surgery & 128848 & 647 & 0.84 & 94854 & 526 & 0.97 \\
\hline Esophageal cancer surgery & 24224 & 493 & 1.98 & 21020 & 551 & 5.80 \\
\hline
\end{tabular}

*CABG + single valve surgery + Acute type A dissection surgery

** reference \#6 
Table 2. Hospital volume and mortality: Crude vs. EB mortality for 5 years

\begin{tabular}{|c|c|c|c|c|c|c|c|c|c|}
\hline \multirow[b]{2}{*}{ Acquired heart disaese } & \multirow{2}{*}{$\begin{array}{c}\text { Number of hospitals } \\
522\end{array}$} & \multirow{2}{*}{$\begin{array}{c}\text { Number of operations } \\
141181\end{array}$} & \multirow{3}{*}{$\begin{array}{c}\text { Crude } \\
\text { EB }\end{array}$} & \multicolumn{3}{|c|}{$\begin{array}{c}\text { 30-day mortality* } \\
\text { (mea } \pm \text { SD, \%) }\end{array}$} & \multirow{2}{*}{$\begin{array}{c}\begin{array}{c}\text { Variation } \\
\text { coefficient }\end{array} \\
111.8\end{array}$} & \multirow{2}{*}{$\begin{array}{c}\begin{array}{c}\text { Pearson's correlation coefficient for } \\
\text { hospital volume and mortality* }\end{array} \\
-0.186\end{array}$} & \multirow{2}{*}{$\begin{array}{c}\text { p value } \\
0.0005\end{array}$} \\
\hline & & & & 3.40 & \pm & 3.80 & & & \\
\hline & & & & 3.08 & \pm & 1.64 & 53.4 & -0.234 & $<.0001$ \\
\hline \multirow[t]{2}{*}{ Elective + emergency CABG } & 518 & 85600 & Crude & 2.15 & \pm & 3.11 & 144.8 & -0.168 & 0.0001 \\
\hline & & & EB & 1.80 & \pm & 1.00 & 55.5 & -0.208 & $<.0001$ \\
\hline \multirow[t]{2}{*}{ Elective CABG } & 518 & 72937 & Crude & 1.12 & \pm & 2.10 & 186.4 & -0.133 & 0.0024 \\
\hline & & & EB & 0.87 & \pm & 0.47 & 54.7 & -0.148 & 0.0008 \\
\hline \multirow[t]{2}{*}{ Emergency CABG } & 482 & 12663 & Crude & 8.69 & \pm & 13.01 & 149.6 & -0.169 & 0.0002 \\
\hline & & & $\mathrm{EB}$ & 6.63 & \pm & 3.08 & 46.4 & -0.195 & $<.0001$ \\
\hline \multirow[t]{2}{*}{ Single-valve surgery } & 514 & 41486 & Crude & 3.21 & \pm & 5.70 & 177.4 & -0.150 & 0.0007 \\
\hline & & & EB & 2.50 & \pm & 0.93 & 37.3 & -0.212 & $<.0001$ \\
\hline \multirow[t]{2}{*}{ Surgery for acute type A dissection } & 477 & 14095 & Crude & 13.41 & \pm & 15.45 & 115.2 & -0.176 & 0.0001 \\
\hline & & & EB & 10.81 & \pm & 3.94 & 36.5 & -0.143 & 0.0017 \\
\hline \multirow[t]{2}{*}{ Open heart surgery for newborns } & 105 & 2825 & Crude & 11.80 & \pm & 14.42 & 122.2 & -0.108 & 0.2731 \\
\hline & & & EB & 10.68 & \pm & 5.30 & 49.6 & -0.168 & 0.0871 \\
\hline \multirow[t]{2}{*}{ Open heart surgery for infants } & 115 & 10249 & Crude & 3.78 & \pm & 7.19 & 190.4 & -0.151 & 0.1078 \\
\hline & & & EB & 2.78 & \pm & 1.22 & 43.8 & -0.259 & 0.0052 \\
\hline \multirow[t]{2}{*}{ Surgery for lung cancer } & 647 & 128848 & Crude & 0.84 & \pm & 4.07 & 485.5 & -0.094 & 0.0163 \\
\hline & & & EB & 0.42 & \pm & 0.19 & 44.2 & -0.077 & 0.0507 \\
\hline \multirow[t]{2}{*}{ Surgery for esophageal cancer } & 493 & 24224 & Crude & 1.98 & \pm & 6.12 & 308.7 & -0.082 & 0.0673 \\
\hline & & & EB & 1.18 & \pm & 0.86 & 73.4 & -0.098 & 0.0302 \\
\hline
\end{tabular}

* 5-year average 
Table 3. Number of hospitals with "inferior" outcomes assessed by EB mortality

\begin{tabular}{|c|c|c|c|}
\hline Type of surgery & Hospital volume* & No. of hospitals & $\begin{array}{c}\text { Number of hospitals } \\
\text { with "inferior " outcomes }\end{array}$ \\
\hline \multirow[t]{4}{*}{ Total acquired heart disease } & $0-49$ & 312 & $18(3.4 \%)$ \\
\hline & $50-99$ & 145 & $8(1.5 \%)$ \\
\hline & 100-199 & 53 & $1(0.2 \%)$ \\
\hline & $200-$ & 12 & $1(0.2 \%)$ \\
\hline \multirow[t]{4}{*}{ Elective + emergency CABG } & $0-24$ & 245 & $2(0.4 \%)$ \\
\hline & $25-49$ & 183 & $2(0.4 \%)$ \\
\hline & $50-99$ & 71 & $1(0.2 \%)$ \\
\hline & $100-$ & 19 & 0 \\
\hline \multirow[t]{4}{*}{ Elective CABG } & $0-24$ & 294 & 0 \\
\hline & $25-49$ & 155 & 0 \\
\hline & $50-99$ & 57 & 0 \\
\hline & $100-$ & 12 & 0 \\
\hline \multirow[t]{4}{*}{ Emergency CABG } & $0-9$ & 417 & 0 \\
\hline & $10-19$ & 48 & 0 \\
\hline & $20-29$ & 10 & 0 \\
\hline & $30-$ & 7 & 0 \\
\hline \multirow[t]{4}{*}{ Single valve surgery } & $0-19$ & 377 & 0 \\
\hline & 20-39 & 105 & 0 \\
\hline & $40-59$ & 22 & 0 \\
\hline & $60-$ & 10 & 0 \\
\hline \multirow[t]{4}{*}{ Surgery for acute type A dissection } & $0-9$ & 406 & $3(0.6 \%)$ \\
\hline & $10-19$ & 51 & 0 \\
\hline & $20-29$ & 16 & $1(0.2 \%)$ \\
\hline & $30-$ & 4 & 0 \\
\hline \multirow[t]{4}{*}{ Open heart surgery for newborns } & $0-9$ & 96 & $2(1.8 \%)$ \\
\hline & $10-19$ & 8 & 0 \\
\hline & $20-29$ & 2 & 0 \\
\hline & $30-$ & 3 & 0 \\
\hline \multirow[t]{4}{*}{ Open heart surgery for infants } & $0-19$ & 78 & 0 \\
\hline & 20-39 & 27 & $1(0.8 \%)$ \\
\hline & $40-59$ & 4 & 0 \\
\hline & $60-$ & 6 & 0 \\
\hline \multirow[t]{4}{*}{ Surgery for lung cancer } & $0-49$ & 462 & 0 \\
\hline & $50-99$ & 137 & 0 \\
\hline & 100-199 & 41 & 0 \\
\hline & $200-$ & 7 & 0 \\
\hline \multirow[t]{4}{*}{ Surgery for esophageal cancer } & $0-19$ & 428 & $1(0.2 \%)$ \\
\hline & 20-39 & 43 & 0 \\
\hline & $40-59$ & 12 & 0 \\
\hline & $60-$ & 10 & 0 \\
\hline
\end{tabular}

* Mean number of surgery per year

** Reference is mean EB mortaloty for 5-year average 